\title{
Research and Development of a Supporting Information System for Optimization of Salmon Release Operations and Monitoring the Coastal Environment on the Okhotsk Coast, Japan
}

\author{
Sei-Ichi Saitoh ${ }^{1,2}$, Yasuyuki Miyakoshi ${ }^{3}$, Fumihiro Takahashi ${ }^{4}$, Takafumi Hirata ${ }^{1}$, Irene D. Alabia ${ }^{1}$, Takashi \\ Hosokawa $^{5}$, and Tatsuya Miyoshi ${ }^{2,6}$ \\ ${ }^{1}$ Arctic Research Center, Hokkaido University, N21W11, Kita-ku, Sapporo, 001-0021, Japan \\ ${ }^{2}$ NPO Digital Hokkaido Community, 6-1, N7W5, Kita-ku, Sapporo, 060-0807, Japan \\ ${ }^{3}$ Kitami Salmon Enhancement Program Association, 1-5-17, Shinmachi, Abashiri, 093-0046, Japan \\ ${ }^{4}$ Green and Life Innovation, Inc., 16-3-1102, Toyokawa-cho, Hakodate, 040065, Japan \\ ${ }^{5}$ Nitto Seimo Co., Ltd., Hakodate Sales Office, 1-3-1, Nanaehama, Hokuto, 049-0111, Japan \\ ${ }^{6}$ Docon, Co., Ltd., Shin-Ohdori Build., 4-1, Ohdori-Nishi, Chuo-ku, Sapporo, 060-0042, Japan
}

Keywords: chum salmon, release, information system, satellite data, numerical forecast model

\section{Introduction}

Chum salmon (Oncorhynchus keta) is one of the important fishery resources in the North Pacific. Recently, under a changing climate, the return of chum salmon in Hokkaido has begun to decrease. More precise juvenile release operations are required for adapting to climatic changes, including warming sea temperature, and this can be accomplished by modifying the sea entry condition. It is necessary for this precise operation to predict the coastal marine environment in the release period and monitor short-term changes in coastal residency. Miyakoshi et al. (2007) applied satellite sea surface temperature data to compare the release timing of hatchery-reared juvenile chum salmon to spring coastal sea surface temperature during high and low survival periods. They demonstrated that satellite remote sensing and GIS (Geographic Information System) techniques are useful to identify optimum release timing for favorable coastal survival of chum salmon. The main objective of this study is to develop a supporting information system with WebGIS for optimization of salmon release operations and monitoring the coastal environment in the Okhotsk coast, Japan.

\section{Materials and Methods}

The salmon, which travelled to the sea from a river, feeds on zooplankton at a coastal region at a time when the water temperature is roughly $8-13^{\circ} \mathrm{C}$; here the salmon grows until it begins its migration to offshore waters. The favorable water temperature of the area along the coast exists for a short period and when temperatures reach more than $13^{\circ} \mathrm{C}$ earlier, a juvenile salmon can only grow in a limited area along the shore (Miyakoshi 2018). It was recently pointed out that this is one of the factors driving the recent decrease in salmon resources. We expect that we can release juvenile salmon at a more appropriate time through the implementation of a system, which can predict the coastal water temperature before the release time.

We developed a supporting information system for the optimization of salmon release operations on the Okhotsk coast. This system was designed as a web-based visualization tool with two service sites, i.e., the monitoring of marine environment (marine site) and supporting of salmon release operation (release site) (Fig.1).

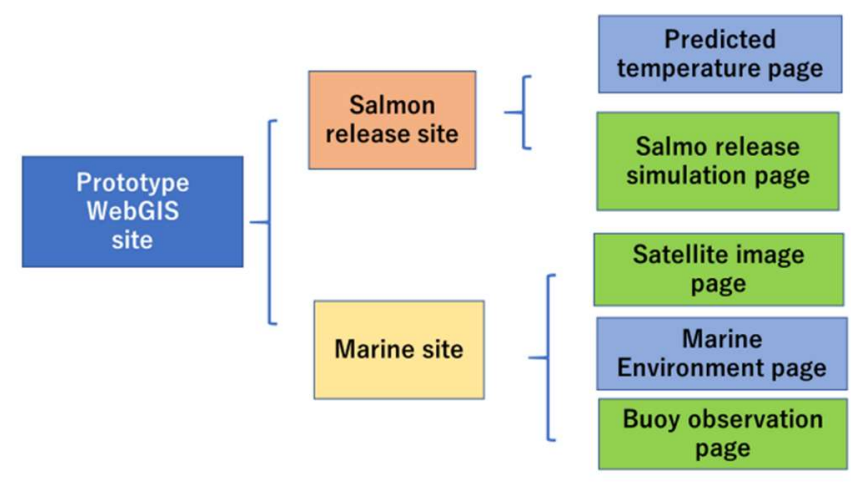

Fig. 1. Structure of prototype Web-GIS.

All correspondence should be addressed to S. Saitoh. 
To predict the SST over the next three months, we employed an Auto Regression (AR) model in R package (https://www.econometrics-with-r.org/14-3-autoregressions.html) using the long term Satellite SST datasets, GHRSST Level 4 MUR Global Foundation Sea surface Temperature analysis (v4.1)

(https://podaac.jpl.nasa.gov/dataset/MUR-JPL-L4-GLOB-v4.1) from 2003 to 2020 . We applied this AR model to estimate the days when water temperature reached $5-13^{\circ} \mathrm{C}$, representing the coastal stay period (Kobayashi 1977). When we can estimate the days of favorable water temperature for release, we can estimate the final fork length at offshoring time with a chum salmon growth model with back-calculation method (Smale and Taylor 1987; Campana 1990). We include this estimation system as a simulator function in release site.

To display short term monitoring of the marine environment (sea temperature, salinity, current, and water masses in various layers), we employ the output of an eddy-resolving analysis model based on four-dimensional variational assimilation and a high $(2 \mathrm{~km})$ resolution forecast model covering Japanese coastal areas developed by the Japan Meteorological Agency (Sakamoto et al. 2019). The Soya warm current is a very important marine system occupying the coastal environment along the Okhotsk coast (Ohshima et al. 2017; Karaki et al. 2018). We applied the water mass classification definition (Takizawa 1982) to distinguish water mass, including Soya warm current, using the numerical forecast model output.

\section{Results and Discussion}

In the marine site (Fig.2), we employed the output of an eddy-resolving analysis model based on fourdimensional variational assimilation and a high $(2 \mathrm{~km})$ resolution forecast model covering Japanese coastal areas developed by the Japan Meteorological Agency. We also use GCOM-C satellite SGLI data, sea surface temperature (SST) and chlorophyll-a, with $250 \mathrm{~m}$ spatial resolution operated by JAXA.

\section{Prototype WebGIS (Marine Site)}
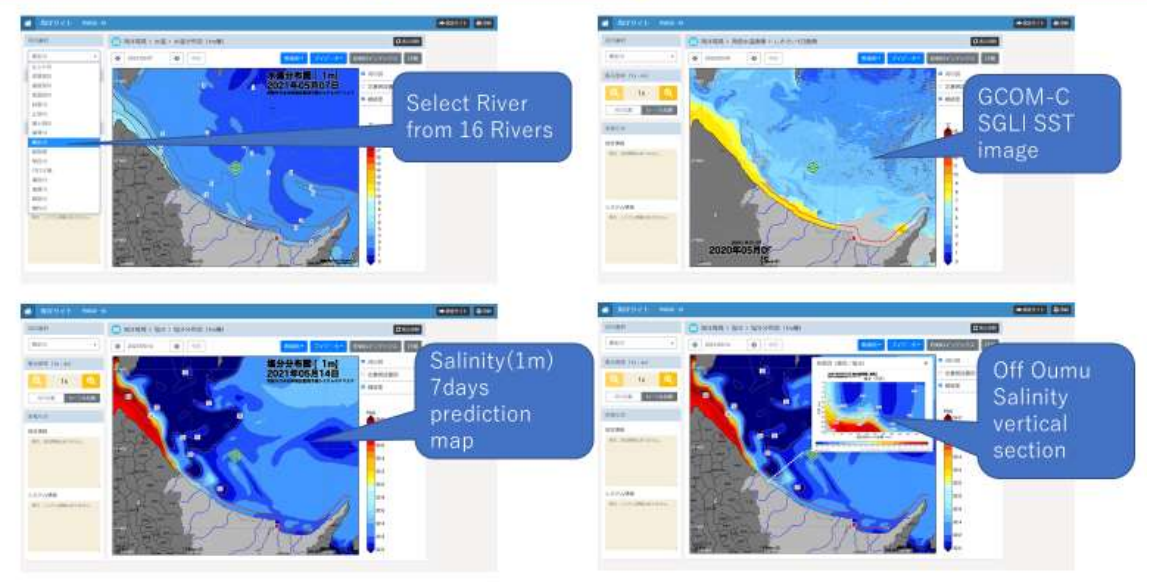

\section{Prototype WebGIS (Salmon Release Site)}
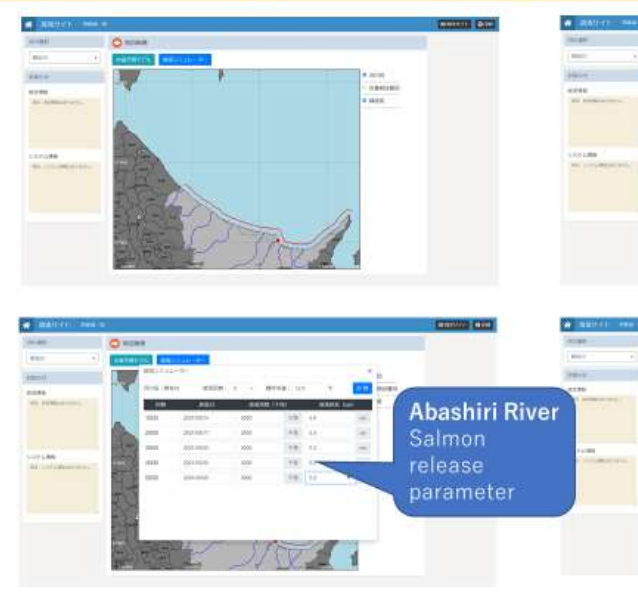

Fig. 2. Example of marine site in prototype Web-GIS.

Fig. 3. Example of release site in prototype Web-GIS. 
In the release site (Fig.3) there are two functions, one is the SST prediction function and the other is the salmon release simulation function. On the SST prediction page, we have obtained the next three months of SST predictions in each of 16 rivers along the Okhotsk coast. On the salmon release simulation page, when we input the number of the release operation, date, release fork length, and number of release salmon, we can then obtain the mean fork length, which is one of the indices of survival/return rate in the period of offshoring from coastal residency. When we change the input parameters, we can turn the final offshoring mean folk length as large as possible.

\section{Concluding Remarks}

To optimize the salmon release operation, we developed a prototype Web-GIS as a visualization tool that incorporates a salmon release simulation function. It might be useful during the preparation of release and a release date decision by using water temperature predictions over three months in advance. A prediction map of the marine environment from numerical model outputs, and a week ahead forecast of water temperature, can assist in the release timing during the short time of release operations. The release simulator function can help in risk management through a more accurate release operation.

We challenge to have a co-work, co-production, and co-design with Kitami Salmon Enhancement Program Association to develop information service for optimum salmon release operation in the Okhotsk coast, Hokkaido, Japan. We started to use the prototype system for the salmon release season in spring 2021 and further research and development can improve the chum salmon enhancement operation in the future.

Acknowledgments-This work was supported by the Space application model demonstration projects 2020 type1, Cabinet Office, Government of Japan. This work was implemented in cooperation with the Kitami Salmon Enhancement Program Association. The ten-year reanalysis dataset of an operational system for monitoring and forecasting coastal and open-ocean status around Japan was provided by the Meteorological Research Institute, Japan Meteorological Agency (JMA). GCOM-C satellite SGLI data product was provided by the Japan Aerospace Exploration Agency (JAXA) through G-Portal site.

\section{REFERENCES}

Campana, S.W. 1990. How reliable are growth back-calculations based on otoliths? Can. J. Fish. Aquat. Sci. 47: 2219-2227.

Karaki, T., H. Mitsudera, and H. Kuroda. 2018. Buoyancy shutdown process for the development of the baroclinic jet structure of the Soya Warm Current during summer. J. Oceanogr. 74: 339-350. doi:10.1007/s10872-018$0465-1$.

Kobayashi, T. 1977. Ecology of juvenile salmon in early marine life stage. Bull. Jpn. Soc. Fish. Oceanogr. 31: 3944. (In Japanese)

Miyakoshi, Y., S.I. Saitoh, A. Matsuoka, M. Takada, H. Asami, M. Fujiwara, and M. Nagata. 2007. Comparison of release timing of hatchery-reared juvenile chum salmon (Oncorhynchus keta) to spring coastal sea surface temperature during high and low survival period. In GIS/Spatial Analysis in Fishery and Aquatic Sciences 3: $227-239$.

Miyakoshi, Y. 2018. Current status of chum salmon stocks in Hokkaido. Aquabiology 40: 330-334. (In Japanese with English abstract)

Ohshima, K., L., D. Shimizu, N. Ebuchi, S. Morishima, and H. Kashiwase. 2017. Volume, heat, and salt transports through the Soya Strait and their seasonal and interannual variations. J. Phys. Oceanogr. 47(5): 999-1019. doi: 10.1175/JPO-D-16-0210.1.

Sakamoto, K., H. Tsujino, H. Nakano, S. Urakawa, T. Toyoda, N. Hirose, N. Usui, and G. Yamanaka. 2019. Development of a 2-km resolution ocean model covering the coastal seas around Japan for operational application. Ocean Dyn. 69: 1181-1202. doi: 10.1007/s10236-019-01291-1.

Smale, M.A., and W.W. Taylor. 1987. Sources of back-calculation error in estimating growth of lake whitefish. In Age and growth of fish. Edited by R.C. Summerfelt and G.E. Hall. Iowa State University Press, Ames.

Takizawa, T. 1982. Characteristics of the Soya warm current in the Okhotsk Sea. J. Oceanogr. Soc. Japan. 38: 281-292. 